Contents available at: Sri Lanka Journals Online

\title{
Characterization of Conserved Sugarcane (Saccharum spp.) Germplasm for Parental Selection in Directional Breeding of Economically Important Traits
}

\author{
B. Kiriwaththuduwa ${ }^{1 *}$, A. Wijesuriya ${ }^{1}$, T.D. Silva ${ }^{2}$, S.W. Ranwala ${ }^{2}$, W. Wijesuriya ${ }^{3}$ \\ ${ }^{1}$ Sugarcane Research Institute, Uda Walawe, Sri Lanka. \\ ${ }^{2}$ University of Colombo, Colombo, Sri Lanka \\ ${ }^{3}$ Rubber Research Institute of Sri Lanka, Agalawatte, Sri Lanka
}

\section{ARTICLE INFO}

\section{Article history:}

Received: 11 August 2020

Revised version received: 25 September 2020

Accepted: 26 October 2020

Available online: 1 April 2021

\section{Keywords:}

Germplasm

Proven crossing system

Sri Lanka

Sugarcane breeding

\section{Citation:}

Kiriwaththuduwa, B., Wijesuriya, A., Silva, T.D., Ranwala, S.W. and Wijesuriya, W. (2021). Characterization of Conserved Sugarcane (Saccharum spp.) Germplasm for Parental Selection in Directional Breeding of Economically Important Traits. Tropical Agricultural Research, 32(2): 179-190.

DOI: http://doi.org/10.4038/tar.v32i2.8465

Kiriwaththuduwa, B.

https://orcid.org/0000-0002-5560-1386

\section{ABSTRACT}

Enhancement of sugar production in Sri Lanka is very important since a large amount of foreign exchange is spent on sugar importation every year. Cultivation of improved varieties developed through proven crosses involving selected parents, for desired cane and sugar yield components, is a necessity to reach the production targets in Sri Lanka. The present study focused on the evaluation of 509 sugarcane parental accessions (Saccharum spp.) for important cane and sugar yield traits. Twelve different cane and sugar yield components; plot weight, stalk length, stalk diameter, number of stalks per plots, hand refractometer brix, rind hardness, laboratory brix, pol in juice, purity, pure obtainable cane sugar, fibre percent fresh weight and sugar yield per plot were measured or estimated. The data were statistically analyzed for testing significance of variance ratios (ANOVA), phenotypic correlations, clustering of parental clones and estimation of breeding values of the parental clones. The results revealed stalk length and number of stalks to be the major determinants of cane yield. A total of 2,500 bi-parental crossing combinations were identified from the selected parental accessions with the best breeding values for the development of high cane and high sugar yielding progenies. The accessions H 820778, M 1356, SL 89 2688, SLC 87 04, SLC 08 62, SLC 08 106, SLC 1205 and SLC 9120 were identified as the most promising parents to be used in simultaneous improvement of cane yield and sugar content with moderate fibre content.

*Corresponding author: kiriwaththuduwab@gmail.com 


\section{INTRODUCTION}

Sugarcane (Saccharum) is a perennial C4 plant which belongs to the family Poaceae. It is cultivated in tropical and subtropical countries exclusively for sugar production. About $75 \%$ of global sugar production is accounted for by sugarcane, and the rest is produced from sugar beet (Conterras et al., 2009). It had been projected that sugarcane will contribute to $86 \%$ of sugar production by the year 2025 (OECD-FAO, 2018). Asia is the highest consumer of sugar in the world while India and Pakistan are the largest sugar producers and consumers in South Asia (OECD-FAO, 2018). It is expected that South Asia may face overall food shortage including sugar due to rise in population and therefore, it is imperative to these countries to become self-sufficient with respect to sugar production in the decades to come (Milovanovic and Smutka, 2016).

In Sri Lanka, commercial sugar manufacturing was initiated in 1960s with the commission of Hingurane and Kantale sugar factories. However, currently the sugar factories located at Sevanagala, Pelwatte and Galoya with total cane crushing capacity of 6550 TCD (tons of cane per day) (Keerthipala, 2014) produce about 52,000 to 60,000 metric tons of sugar per year satisfying only $8-10 \%$ of the domestic requirement (Central Bank of Sri Lanka, 2019), while the rest was imported. As indicated in the Development Policy for Sugar Industry in Sri Lanka (Ministry of Finance, 2016), it is necessary to expand cultivation, use improved sugarcane varieties and adopt better management practices and modern technologies (Sugarcane Research Institute, 2013) to achieve the targets of $40 \%$ self-sufficiency in sugar by 2020 and $100 \%$ by 2030. As per the Central bank of Sri Lanka (2016; 2017; 2018; 2019), cultivation of high yielding sugarcane varieties, access to irrigation systems, increasing sugarcane cultivation at out-growers and achieving high sugar recovery rate contribute to the increase in sugar production. Sugarcane has a long crop cycle and its cultivation requires costly inputs including machinery, labour and agrochemicals. Therefore, to prevent farmers from converting sugarcane with other economically viable crops such as maize and banana (Keerthipala, 2016; De Silva et al., 2019), it is important to provide high cane and sugar yielding varieties with optimum fibre content that are resistant for different abiotic and biotic conditions for cultivation.

Although, S. officinarum L. (noble cane) has desirable industrial properties and high sucrose levels, the higher cane and sugar yields, adaptability to varying environmental conditions and disease and pest resistance of modern commercially-grown sugarcane varieties have been achieved through interspecific hybridization followed by back-crossing between $S$. officinarum and $S$. spontaneum. The success of breeding programs depends on several factors among which the choice of parents with good performance for the traits of economic values is critical to maximize the chance of obtaining superior genotypes in the progeny. Hence, germplasm evaluation, parental selection for hybridization and progeny selection are important steps that determine the efficiency of sugarcane improvement programs. Genetic resources conserved and maintained by the Sugarcane Research Institute (SRI), Sri Lanka comprise a rich collection of 1448 accessions representing pure $S$. officinarum, $S$. spontaneum, Erianthus arundinaceous, Miscanthus japonica and commercial clones (Saccharum hybrid spp.), first, second and third generations of inter-generic and inter-specific hybrids and clones developed through callus culture technique.

Sugarcane crop improvement begins with hybridization of these parental clones to create genetically variable seedling populations. At present, parents for hybridization are selected based on the results of germplasm evaluation and quantitative genetic experiments conducted by several research teams (Sunil, 1995; Sunil and Lawrence, 1996; Wijesuriya et al., 1993; 1997) and Wijesuriya (2012). However, proven parents and proven crossing systems for directional breeding of sugarcane, for high sugar, high cane yield, and for disease and pest resistance are yet to be developed in Sri Lanka. Moreover, a limited number of accessions evaluated in those experiments provide limited information for developing a proven mating system.

Sugarcane breeders contemplating on new germplasm in a breeding program need to know the characteristics of the many classes and clones of materials available and how they might make a logical selection of parents from it (Mbuma et al., 2019). Hence, this research was undertaken with the objective of determining breeding values of parental clones in the germplasm collection for yield, sugar and fibre components as well as estimating the association between cane and sugar yield components and fibre content to identify parents for the development of core-collections to be used in directional breeding of sugarcane simultaneously for high cane yield, high sucrose content and optimum fibre content. The parents selected through this study are to be included in the core-collection to develop a proven parent mating system involved with 'bi-parental crossing' and 'poly-crossing' techniques aiming at developing 
high cane and sugar yielding varieties with optimal fibre content.

\section{MATERIALS AND METHODS}

\section{Establishment of field experiment}

The field experiment designed for the evaluation of selected 509 parental clones (treatments) comprised 136 pure Saccharum officinarum cultivars, 15 Saccharum spontaneum clones, 19 Erianthus arundinaceus clones and 339 Saccharum spp. hybrids. These parental clones were selected out of 1460 accessions conserved in the sugarcane germplasm in Sri Lanka using a random number generator. The experiment was conducted at the Research Farm of the Sugarcane Research Institute, Uda-Walawe where the coordinates of the experimental site are $6^{\circ} 21^{\prime} \mathrm{N}$ Latitude and $80^{\circ} 48^{\prime}$ E Longitude.

The field experiment was established in the land prepared following ridge and furrow system to facilitate furrow irrigation. The furrow spacing of $1.37 \mathrm{~m}$ ( $4.5 \mathrm{feet}$ ) and the furrow depth of $25 \mathrm{~cm}$ (10 inches) were maintained throughout the field experiment. All treatments were tested in a Completely Randomized Design (CRD) with two replicates. The parental clones were planted in 1meter-long plots leaving $0.5 \mathrm{~m}$ gap between two plots in the furrows. Five three-budded stem cuttings (setts) were planted in a plot. Crop management practices such as gap filling, fertilizer application, earthing-up, weed management, irrigation etc. were done as recommended by the Sugarcane Research Institute.

\section{Harvesting and data collection}

Only the millable stalks were used for collection of data on yield and quality parameters. Number of millable stalks per plots (ST) and plot weight (WT) were recorded initially at harvest and then, a sample of twelve randomly-selected millable stalks were obtained for recording data on stalk length (SL), stalk diameter (DM), rind hardness (RD) and field brix (HB) at the field and ten stalks of the same sample were used for measuring / estimating laboratory brix (Brix), pol percent in juice (Pol) and purity (Pur) at the laboratory. The remaining two stalks were used for measuring fibre percent fresh weight (Fib). Pure obtainable cane sugar (POCS) was calculated using the equation that involves laboratory brix, pol in juice and fibre content. Sugar yield (SY) was calculated by multiplying plot weight (WT) x pure obtainable cane sugar (POCS).

\section{Analysis of data}

Analysis of variance (ANOVA) was performed for the above variables and the means of the characteristics of each accession were compared against the commercial standard Co 775 using Dunnett's test in order to select accessions that possess values higher than the commercial variety. The statistical procedures available in Statistical Analysis System (SAS University edition) and the Genstat-ver18 were employed in statistical analyses.

Phenotypic correlations were estimated for each pair of characteristics using the phenotypic values of accessions. Sugar yield per plot was not considered in correlation analysis since it is calculated using plot weight and POCS.

The phenotypic correlation is;

$r_{p}=\frac{C O V_{p}}{\sigma_{p x}+\sigma_{p y}}$

where, $\operatorname{COV}_{\mathrm{p}}$ is phenotypic covariance, $\sigma_{\mathrm{px}}$ and $\sigma_{\mathrm{py}}$ are phenotypic standard deviations of characteristics $\mathrm{X}$ and $\mathrm{Y}$, respectively (Falconer, 1989).

Agglomerative hierarchical approach was employed in cluster analysis as it is the most widely-used method compared to divisive methods (Rencher, 2002). Statistical software, Genstat version 18 was used in cluster analysis. Breeding values (BVs) of the accessions were estimated using the following equation proposed by Marshall (2008);

$\mathrm{BV}=\mathrm{h}^{2} \mathrm{~N}(\mathrm{P}-\overline{\mathrm{P}})$

where, BV is breeding value, $\mathrm{h}^{2} \mathrm{~N}$ is narrow sense heritability, $\mathrm{P}$ is phenotypic value of the accession, and $\bar{P}$ is mean of the parental population.

The narrow sense heritability values of the characteristics estimated by Wijesuriya (2012) were used for the estimation of breeding values of the accessions and these values are presented in Table 1. Breeding values for sugar yield per plot was not estimated as narrow sense heritability for sugar yield was not available under local conditions. 
Table 1: Narrow sense heritability values of the characteristics used for estimation of breeding values of the accessions.

\begin{tabular}{lc}
\hline Characteristics & $\begin{array}{c}\text { Narrow-sense } \\
\text { heritability }\left(\mathbf{h}^{2} \mathrm{~N}\right)\end{array}$ \\
\hline Stalk length & 0.38 \\
Stalk diameter & 0.60 \\
Number of stalks per plot & 0.54 \\
Plot weight & 0.40 \\
Hand refractometer brix & 0.73 \\
Laboratory brix & 0.69 \\
Pol in juice & 0.58 \\
Purity & 0.52 \\
POCS & 0.42 \\
Fibre percent & 0.53 \\
\hline
\end{tabular}

Source: Wijesuriya (2012).

\section{RESULTS AND DISCUSSION}

\section{Selection of parents based on ANOVA and mean separation}

Analysis of variance indicated that there were significant differences among the accessions for all the characteristics, revealing that there is sufficient variability among the accessions for selection of better parental clones for making directional crosses for improvement in desired characteristics. Two variables; plot weight (WT) and pure obtainable cane sugar (POCS), were considered for mean separation because in this study cane yield and sugar content in cane were approximated by plot weight and POCS respectively.

Comparison of these two variables in the accessions against the standard variety Co 775 using Dunnett's procedure revealed that nine accessions (PH 86 103, SL 73 04, SL 84 13, SL 92 492, SL 95 4098, SLC 91 36, SLC 12 08, LF 75 423, LF 78 960) had positive and significant mean differences from the standard at 0.05 level for high cane yield. Furthermore, 40 accessions (LF 63 70, LF 63 71, LF 6375, LF 65 3666, LF 74 3466, LF 75 2154, LF 75 423, LF 76 5296, LF 78 960, SES 75, SL 85 11, SL 96 656, SLC 08 102, SLC 12 77, SLC 12 83, SLC 81 37, SLC 89 20, SLC 89 22, SLC 89 23, SLC 89 25, SLC 89 27, SLC 89 32, SLC 90 01, SLC 90 08, SLC 91 37, SLC 91 38, SLC 92 32, SLC 92 51, SLC 92 65, SLC 92 66, SLC 92 79, SLC 92 82, SLC 92 85, SLC 92 87, SLC 92 92, SLC 92 96, SLC 92 98, SLC 92 99, SLC 93 01, SLT 4222) were identified with a positive and significant mean difference against the standard Co 775 at the same significant level (0.05) for high sugar content.

These accessions are considered to be the most suitable parental clones to be used or included in the core-collection for simultaneous improvement of cane yield and sugar content. However, the rest of the accessions which are more or less similar to the mean of Co 775, can also be considered in the parental collection.

\section{Phenotypic correlations}

The relationship of the characteristics that determine sugar yield and cane yield is the main concern of a sugarcane breeder in selection of parents for directional breeding. The magnitude and direction of phenotypic correlation coefficients are important in deciding the characteristics on which selection of parents are to be carried out for directional breeding for cane yield and sugar yield while considering the optimum fiber content in cane. In this analysis, sugar yield per plot (SY) was omitted since the WT and POCS have a strong linear relationship with SY. The phenotypic correlation matrix of the characteristics studied is presented in Table 2. Phenotypic correlations suggested that the clones with a higher number of millable stalks per plot and higher stalk lengths can be taken as prospective parents for directional breeding for cane yield.

As a significant-negative relationship was observed between number of millable stalks per plot and stalk diameter, the clones with a high number of millable stalks with acceptable stalk diameters have to be considered in parent selection for crossing as it determines the juice extraction efficiency in the mills. Comparatively thicker canes produce less number of millable canes and thereby giving considerably-low cane yields. Therefore, selection of parents with acceptable diameters and high stalk lengths is required for directional breeding for cane yield. The association between fiber and POCS was significant, but moderate and negative. Therefore, sugarcane breeders have to pay attention on selecting parents with high cane yields, high sucrose contents and with moderate fiber contents for breeding for high cane- and high sugar- yields. Nevertheless, selection of parents with high fiber has also become a necessity in breeding energy canes (e-canes) for use with factory modifications. Strong, significant and positive correlations of hand refractometer brix to laboratory brix, pol, purity and POCS observed in the present study have proved that the assessment of varieties for sugar content through hand brix is realistically accurate in initial screening of high sugar parental clones in the germplasm collection. Parents with the highest sugar contents should be identified accurately through POCS for incorporation into the directional crosses of sugarcane for high sugar contents. 
Table 2: The coefficients of phenotypic correlations among the components of cane and sugar yields and fiber content in cane

\begin{tabular}{|c|c|c|c|c|c|c|c|c|c|c|}
\hline & $\begin{array}{l}\text { Laboratory } \\
\text { Brix }\end{array}$ & Pol & Purity & POCS & Fibre & $\begin{array}{l}\text { Stalk } \\
\text { diameter }\end{array}$ & $\begin{array}{l}\text { Stalk } \\
\text { Length }\end{array}$ & $\begin{array}{l}\text { Hand } \\
\text { Brix }\end{array}$ & $\begin{array}{l}\text { Number } \\
\text { of stalks }\end{array}$ & $\begin{array}{l}\text { Plot } \\
\text { weight }\end{array}$ \\
\hline Pol & $0.98^{* * *}$ & & & & & & & & & \\
\hline Purity & $0.82^{* * *}$ & $0.90^{* * *}$ & & & & & & & & \\
\hline POCS & $0.96^{* * *}$ & $0.99^{* * *}$ & $0.91^{* * *}$ & & & & & & & \\
\hline Fibre & $-0.38^{* * *}$ & $-0.42^{* * *}$ & $-0.49 * * *$ & $-0.48^{* * *}$ & & & & & & \\
\hline Stalk diameter & $0.31^{* * *}$ & $0.33^{* * *}$ & $0.35^{* * *}$ & $0.35^{* * *}$ & $-0.57^{* * *}$ & & & & & \\
\hline Stalk length & $0.27^{* * *}$ & $0.25^{* * *}$ & $0.15^{* * *}$ & $0.22^{* * *}$ & $0.12^{* * *}$ & $-0.01^{* * *}$ & & & & \\
\hline Hand brix & $0.88^{* * *}$ & $0.88^{* * *}$ & $0.77^{* * *}$ & $0.88^{* * *}$ & $-0.48^{* * *}$ & $0.41^{* * *}$ & $0.21^{* * *}$ & & & \\
\hline Number of stalks & $0.04^{\mathrm{NS}}$ & $0.03^{\mathrm{NS}}$ & $0.01^{\mathrm{NS}}$ & $0.02^{\mathrm{NS}}$ & $0.18^{* * *}$ & $-0.24^{* * *}$ & $0.34^{* * *}$ & $-0.03^{* * *}$ & & \\
\hline Plot weight & $0.33^{* * *}$ & $0.34^{* * *}$ & $0.33^{* * *}$ & $0.34^{* * *}$ & $-0.18^{* * *}$ & $0.31^{* * *}$ & $0.49^{* * *}$ & $0.34^{* * *}$ & $0.67^{* * *}$ & \\
\hline Rind hardness & $-0.06^{\mathrm{NS}}$ & $-.0 .07^{\mathrm{NS}}$ & $-0.11^{\mathrm{NS}}$ & $-0.09^{N S}$ & $0.46^{* * *}$ & $-0.12^{* * *}$ & $0.27^{* * *}$ & $-0.10^{\mathrm{NS}}$ & $0.26^{* * *}$ & $0.22^{* * *}$ \\
\hline
\end{tabular}

*** Significant at $\mathrm{P} \leq 0.001$; NS Not significant 
Cane yield and sugar content in cane are complex characteristics which can be improved independently and simultaneously by manipulating their components during variety selection and breeding through the choice of parental clones. Comparatively thinner canes in the population have high fiber contents, and thicker canes are associated with comparatively low fiber contents. Rind hardness reasonably assesses fiber content in cane. As it is a nondestructive test, parental clones can be screened initially for fiber using rind hardness.

\section{Cluster analysis}

Cane yield components based cluster analysis classified all the accessions into 8 main groups at 0.9 dissimilarity level (Figure 1), whereas, sugar yield components based cluster analysis classified all the accessions into 5 main categories at the same dissimilarity level (Figure 2). Sugar yield per plot-based cluster analysis classified accessions into 4 main groups at 0.9 dissimilarity level (Figure 3 ) and fiber percentage and rind hardness based cluster analysis resulted in 8 main groups at 0.9 dissimilarity level (Figure 4).

Clustering based on cane yield components sorted 275 accessions into group 1 along with the standard Co 775. The accessions in group 5 of the same cluster had the thickest canes and nearly 25 stalks per plot. Accession in these two cluster groups can be included in the co-parental collection that is to be developed for use in breeding for high cane yield. However, this cluster comprised moderate cane-yielding accessions with the average of $15.93 \mathrm{~kg}$ per plot. The three LF varieties; LF 75 3866, LF 75423 and LF 78960 in group 8 which gave the highest average cane yield per plot of $33.17 \mathrm{~kg}$ produces more than 55 stalks per plot but the stalk diameter was not in the acceptable range and also had very low sugar content detected through POCS. Hence, these varieties can be used for nobilization and not as parents for breeding for high cane yield. The group 7 comprised accessions with comparatively-thinner canes but with comparatively higher number of canes per plot. The accessions in group 6 were more or less similar to the accessions in group 7 but were taller, and produced canes which were over $1.25 \mathrm{~m}$ in height. Stalk length has positive genetic correlation and indirect response to selection for cane yield than direct response to selection for cane yield (Wijesuriya, 1997). Hence, the accessions in group 6 can be incorporated into the parental core-collection for breeding for high cane yielding varieties through inter-cluster crosses between this cluster and clusters 1 , and 5 .

Development of sugarcane varieties with high cane yield, high sugar content and moderate fiber (about 14\%) required for generating energy at the sugar factories is the primary concern of sugarcane breeders. Hence, selection of parental clones directed for simultaneous improvement of cane yield and sugar content has to be performed and these parental clones have to be incorporated into the parental core-collection with moderate fiber content. At the same time sugarcane varieties with high fiber are required for cogeneration of electricity. Therefore, sugarcane breeders are also encouraged to develop sugarcane varieties with high cane yield, high sugar content with high fiber content. The following list of 109 parental clones were identified as being suitable parents for simultaneous breeding for high cane yield, high sugar content and moderate fiber.

The 109 parental clones commonly-classified for high cane yield, high sugar content and moderate fiber

BE 166, CO 8723, CP 72210, H 70144, H 721365, H 737324, K 84200, LF 65 3695, LF 72 442, LF 74 3437, LF 74 4481, LF 75 1036, LF 75 5629, LF 75 800, LF 76 119, LF 77 2263, LF 78 175, LF 78 1763, LF 78 187, LF 81 1077, M 1353, M 223889, M 55560, N 50219, PH 5536, PH 6133, PH 82204, PH 831164, PH 84402, PH 85382, PH 85686, PH 8662, SL 81 06, SL 82 01, SL 82 03, SL 82 05, SL 82 07, SL 82 20, SL 84 14, SL 84 17, SL 84 18, SL 85 03, SL 85 26, SL 87 01, SL 87 08, SL 87 14, SL 87 34, SL 87 38, SL 89 2315, SL 89 2560, SL 89 2569, SL 89 2573, SL 90 4110, SL 90 6088, SL 91 4251, SL 91 4295, SL 91 4300, SL 92 4934, SL 93 1237, SL 93 1466, SL 93 172, SL 93 945, SL 94 2354, SL 94 2764, SL 94 2780, SL 94 2847, SL 94 2916, SL 94 3423, SL 95 4033, SL 95 4422, SL 95 4425, SL 95 4485, SL 95 4497, SL 96 245, SL 96 328, SL 96 656, SL 96 719, SL 97 1220, SLC 08 28, SLC 08 33, SLC 08 54, SLC 08 56, SLC 12 57, SLC 12 70, SLC 12 84, SLC 12 90, SLC 87 06, SLC 91 04, SLC 91 33, SLC 92 35, SLC 92 54, SLT 4222, SLT 4405, SLT 4731, SLT 4732, SLT 4803, SLT 8410, SLT 8413, LF 73 224, N 511260, PH 8470, SL 92 5483, CO 8723, K 84200, LF 77 2263, PH 85382, PH 85686, SLC 12 57, SL 96328. 


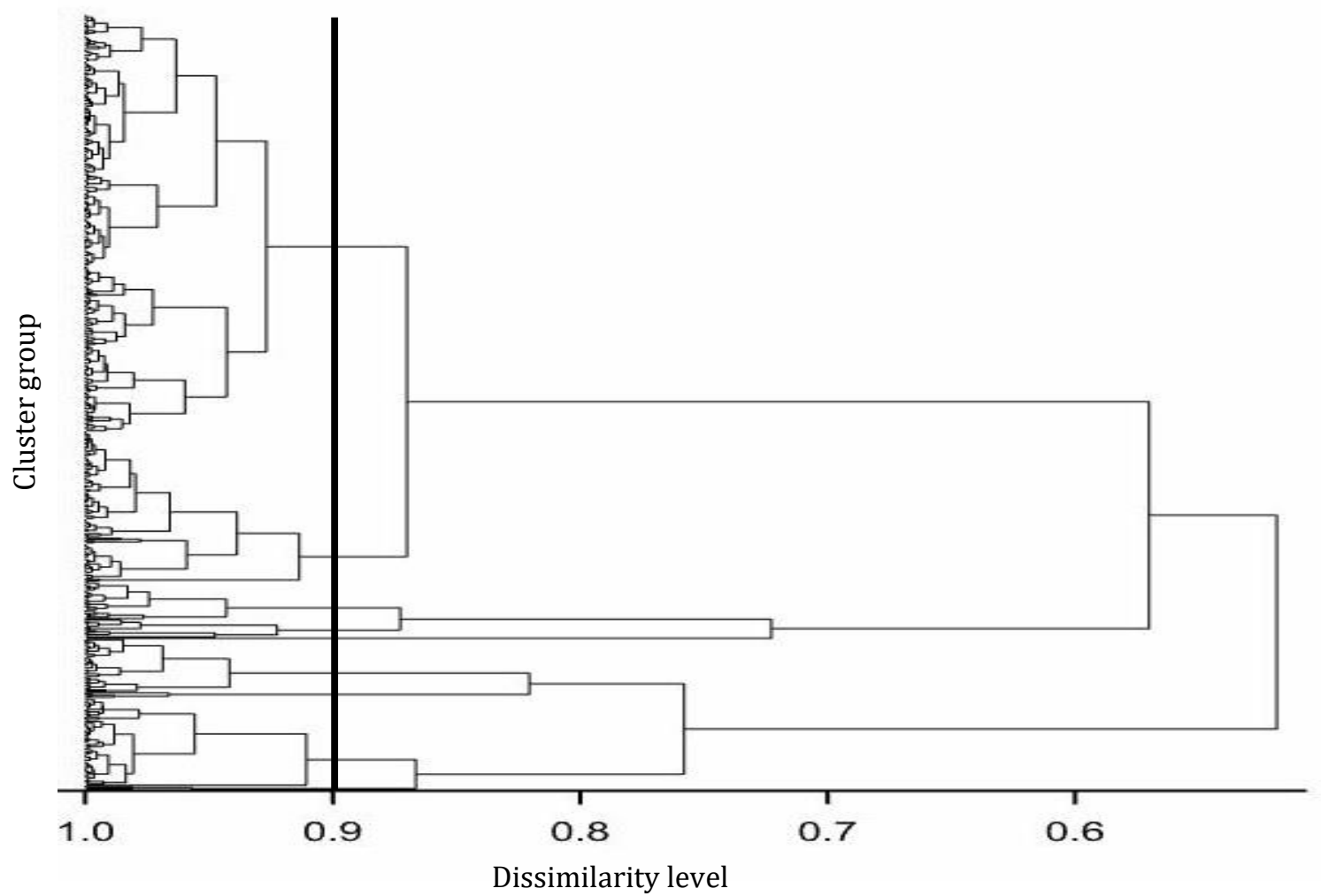

Figure 1: Dendogram produced on plot weight, number of stalks per plot, stalk length and stalk diameter

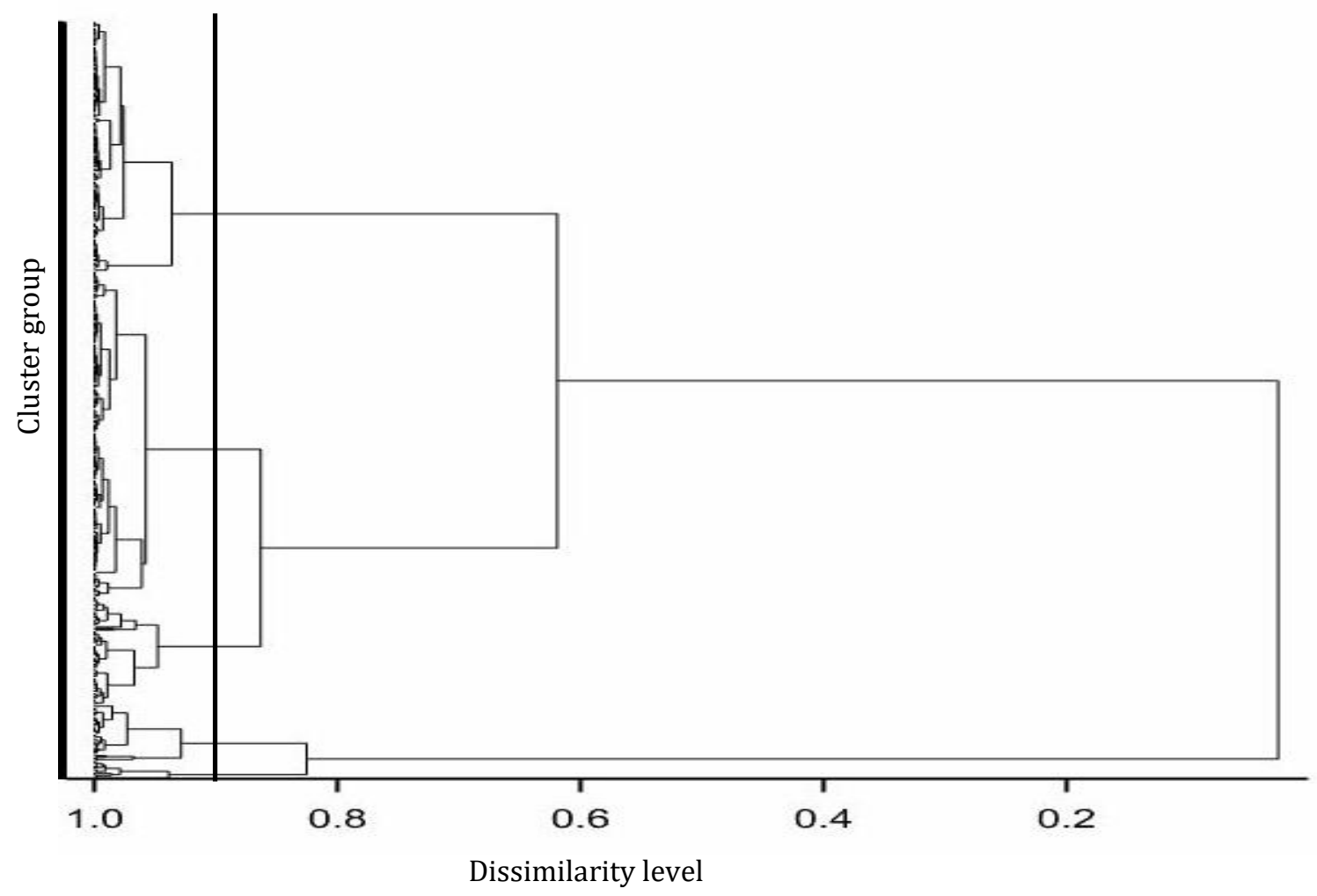

Figure 2: Dendogram produced on laboratory brix, pol, purity and POCS 


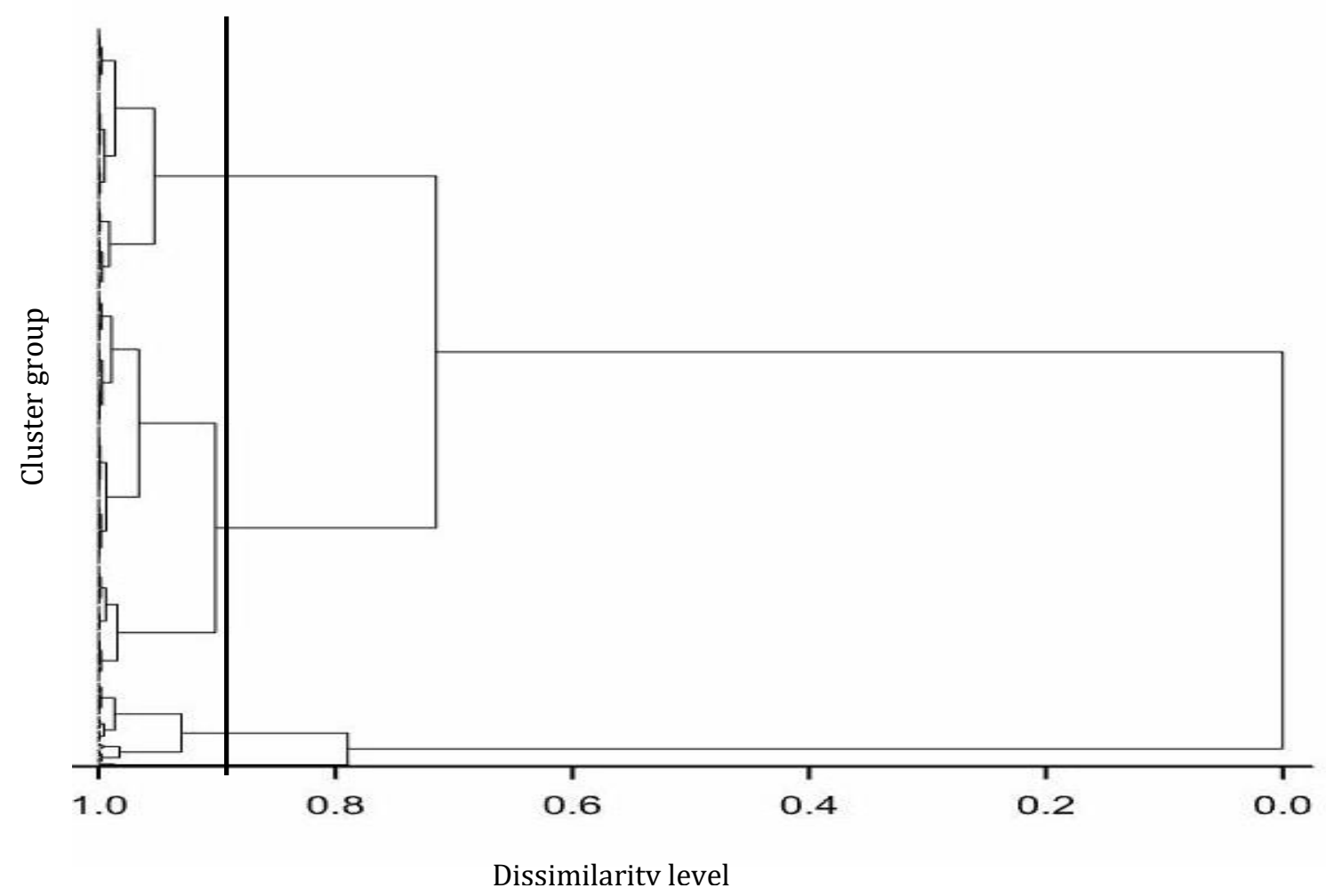

Figure 3: Dendogram produced on sugar yield

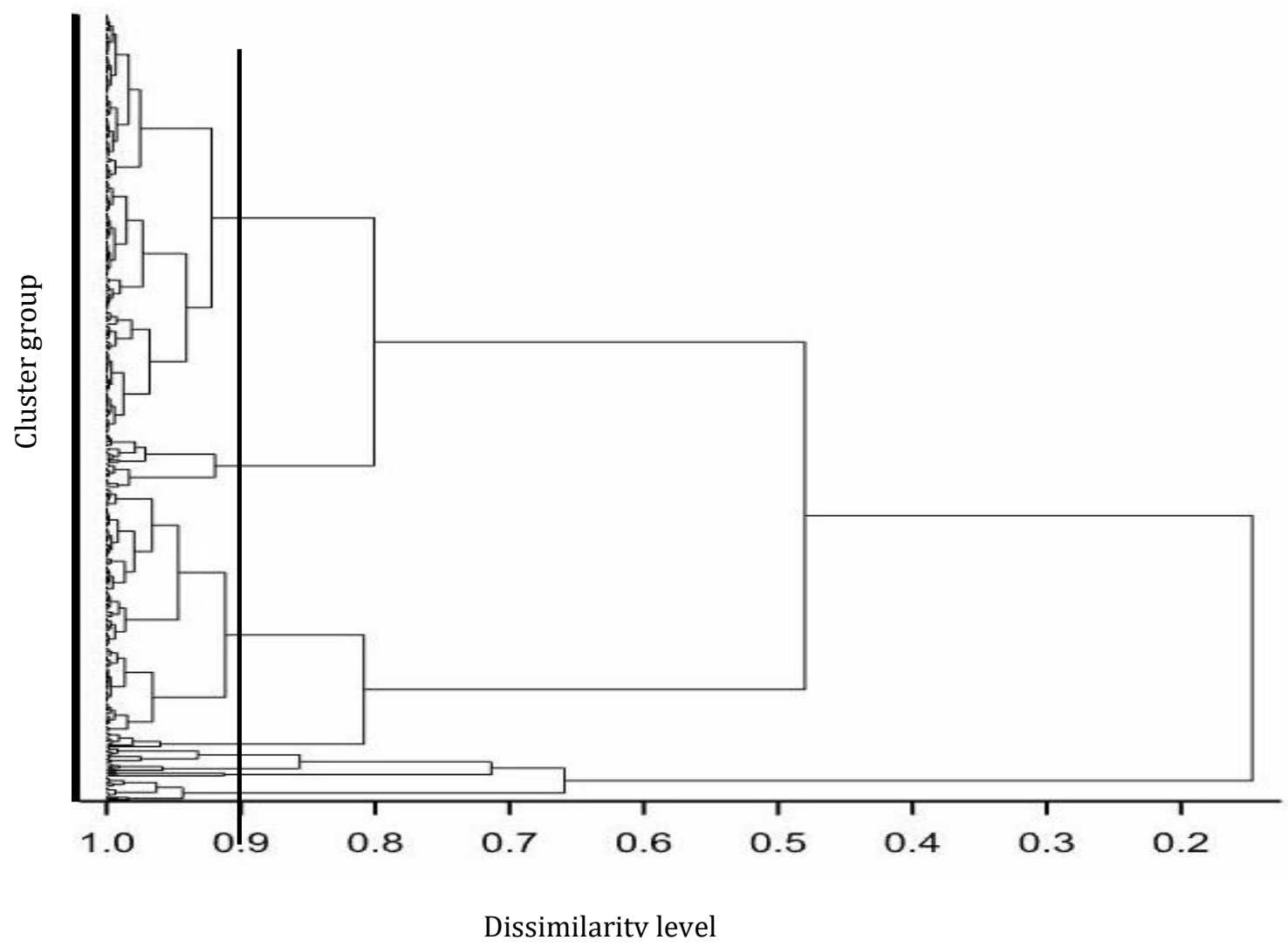

Figure 4: Dendogram produced on fiber percentage and rind hardness 
Furthermore, 38 sugarcane parental clones were identified as being useful for breeding varieties with high cane yield, high sugar content and high fiber content and they are listed below. These parental clones can be used in the crosses directed for simultaneous improvement of these three characteristics.

The parental clones that can be used in the crosses directed for simultaneous improvement of high cane yield, high sugar content and high fiber content

H 721365, H 737324, LF 65 3695, LF 72 442, LF 75 800, LF 76 119, N 50219, PH 82204, PH 831164, PH 84402, SL 82 01, SL 82 03, SL 96 328, SLC 91 33, CO 655, CP 77414, H 575154, LF 51 307, LF 63 65, LF 76 5291, LF 76 789, PH 2098, PH 34144, PH 49005, PH 5989, PH 66106, PH 78490, PH 8093, PH 841014, Q 66, Q 86, SL 81 10, SL 84 227, SL 85 09, SL 85 11, SL 87 103, LF 74 4425, SL 96328.

Since, S. spontanuem and Erianthus arundinaceus cannot be used directly as parents of Saccharum officinarum and Saccharum hybrid spp because of the need of several back crosses (nobilization) in the development of commercial varieties, nine parental clones including $S$. spontaneum and $E$. arundinaceus were identified based on the cluster analysis performed for cane yield and fiber components which can be considered as promising parents for nobilization (Table 3).

Table 3: Parental clones of Saccharum spontaneum and Erianthus arundinaceus with comparatively higher potential to be used in inter-specific and inter-generic crossing programs in sugarcane.

\begin{tabular}{cc}
\hline $\begin{array}{c}\text { Parental } \\
\text { clones }\end{array}$ & \multicolumn{1}{c}{ Species } \\
\hline SLC 9287 & Erianthus arundinaceus \\
SLC 1277 & Saccharum spontaneum \\
SLC 1283 & Saccharum spontaneum \\
SLC 8922 & Saccharum spontaneum \\
SLC 9001 & Saccharum spontaneum \\
SLC 9251 & Saccharum spontaneum \\
SLC 9298 & Saccharum spontaneum \\
SLC 9299 & Saccharum spontaneum \\
SLC 93 01 & Saccharum spontaneum \\
\hline
\end{tabular}

Selection of parents based on breeding values (BVs) and development of proven crossing system

Out of 509 accessions which were tested in this experiment and for which breeding value was calculated, the best 50 breeding values for each of the sugar and yield characteristics, i.e. nearly ten percent of the population, were selected as the parents in crosses to be performed for directional breeding of the respective characteristic. Table 4 illustrates the 50 accessions with the best BV's only for plot weight and POCS as in this study cane yield and sugar yield are estimated through those characteristics. Overall, all these clones in the selected ten percent of the population are the best parents that form respective corecollections for use in crossing and a large number of crossing combinations viz. biparental and poly crosses can be derived out of these parental clones in directional breeding to combine desired characteristics. Out of the selected best 50 parental clones in each of the core-collections developed for high cane yield (classified by BVs of plot weight) and high sugar content (classified by BVs of POCS), 2,500 bi-parental crossing combinations can be made with the direction to develop high cane and high sugar yielding progenies. Table 5 gives a sub-set of parental combinations (25) out of 2,500 to illustrate the expected outcome of the progeny.

In practical situations, cross incompatibilities are experienced and hence, these incompatible cross combinations have to be eliminated from the crossing system which may take several crossing seasons to identify.

The eight common parental clones characterized by BV's of plot weight and POCS namely H 820778, M 1356, SL 89 2688, SLC 08 106, SLC 08 62, SLC 12 05, SLC 8704 and SLC 9120 , bolded in table 4 , can be considered as the most promising parents to be used in simultaneous improvement of cane yield and sugar content. As all these clones have been characterized by cluster analysis as clones with moderate fiber content, the progeny expected out of the crosses involved with these parents may also have moderate amounts of fiber.

Development of a computer program is proposed to select the parental combinations for bi-parental crosses, large number of poly crosses and selfcrosses out of the above core-collection $10 \%$ of the population with the best BVs) developed for high cane yield and high sugar content that can be performed depending on the availability of flowers in a crossing day. 
Table 4: Accessions with the highest breeding values (BVs) for plot weight (WT) and pure obtainable cane sugar (POCS)

\begin{tabular}{|c|c|c|c|c|c|c|c|}
\hline \multicolumn{4}{|c|}{ WT } & \multicolumn{4}{|c|}{ POCS } \\
\hline Accession & BV & Accession & BV & Accession & BV & Accession & BV \\
\hline LF 78960 & 9.37 & SLC 0817 & 4.37 & LF 781172 & 2.51 & SLC 1285 & 1.67 \\
\hline SLC 0812 & 8.37 & SLC 1245 & 4.37 & SL 942802 & 2.2 & SL 8418 & 1.65 \\
\hline SLC 0870 & 7.77 & SLC 0829 & 4.27 & LF 653695 & 2.02 & SL 892688 & 1.55 \\
\hline SLC 0862 & 7.57 & SLC 0832 & 4.27 & LF 782222 & 2.01 & SL 942780 & 1.54 \\
\hline SLC 08110 & 7.37 & SLT 4814 & 4.27 & SL 7229 & 1.98 & M 1356 & 1.54 \\
\hline SLC 0851 & 7.37 & SLC 0879 & 4.17 & SLT 4803 & 1.96 & SL 8220 & 1.54 \\
\hline SLC 1281 & 6.77 & Н 493533 & 4.07 & M 1353 & 1.93 & SL 75388 & 1.52 \\
\hline LF 753866 & 6.57 & M 1356 & 4.07 & SLC 9133 & 1.91 & SLC 8704 & 1.52 \\
\hline SLC 08118 & 6.57 & SL 904989 & 4.07 & SLC 0862 & 1.86 & SL 942847 & 1.51 \\
\hline SL 954129 & 6.43 & M 117677 & 3.97 & SL 8708 & 1.84 & SL 931640 & 1.5 \\
\hline SLC 9120 & 6.27 & PH 84167 & 3.97 & SL 954098 & 1.84 & M 55560 & 1.5 \\
\hline SL 954194 & 5.97 & SLC 8704 & 3.97 & LF 751003 & 1.81 & SL 96719 & 1.49 \\
\hline SLC 08109 & 5.97 & SLT 8419 & 3.97 & Н 820778 & 1.8 & PH 84778 & 1.49 \\
\hline SLC 0860 & 5.97 & SLC 0824 & 3.83 & SL 892315 & 1.79 & SL 924839 & 1.47 \\
\hline SLC 1249 & 5.57 & SL 8703 & 3.77 & SLC 0828 & 1.78 & SL 954243 & 1.47 \\
\hline LF 75423 & 5.17 & SLC 0815 & 3.77 & LF 755629 & 1.78 & SL 8526 & 1.47 \\
\hline SL 8212 & 5.17 & SL 8774 & 3.73 & SLC 9120 & 1.77 & SL 943423 & 1.47 \\
\hline SLC 0847 & 5.17 & PH 841096 & 3.67 & PH 8662 & 1.77 & SL 8417 & 1.47 \\
\hline SL 892688 & 5.07 & SLC 0848 & 3.67 & SLC 08106 & 1.75 & SL 8413 & 1.46 \\
\hline H 820778 & 4.87 & SLC 0852 & 3.67 & C0 8723 & 1.74 & SL 954485 & 1.45 \\
\hline SLC 1280 & 4.77 & LF 75805 & 3.57 & LF 78175 & 1.73 & SL 8714 & 1.44 \\
\hline SL 8505 & 4.57 & SLC 0842 & 3.57 & SL 942354 & 1.71 & SL 931466 & 1.44 \\
\hline SLC 08106 & 4.57 & SLC 1208 & 3.53 & SLC 1205 & 1.71 & SLC 0856 & 1.41 \\
\hline SLC 9105 & 4.57 & SLC 1205 & 3.47 & SLC 0893 & 1.67 & SL 925004 & 1.4 \\
\hline SLC 0816 & 4.37 & SLC 1272 & 3.47 & N 50219 & 1.67 & SLC 1257 & 1.36 \\
\hline
\end{tabular}

\section{CONCLUSIONS}

Out of the 509 sugarcane accessions evaluated in this study nine accessions were superior to the standard check variety Co 775 in cane yield and a further 40 accessions were superior in sugar content. Therefore, these accessions are suitable to be included in the parental core collection for breeding of varieties with high cane yield and sugar content.

Clustering based on cane yield components found 275 accessions grouping together in one cluster along with the standard Co775, indicating their suitability to be included in the parental core collection for performing inter-varietal crosses in breeding for high cane yield. Although $03 \mathrm{LF}$ varieties (LF 75 3866, LF 75423 and LF 78 960) were grouped together in a cluster that had the highest average plot weight they showed very low sugar content and thus were not considered to be suitable as parents in breeding for high cane yield, but were identified as being useful for nobilization of canes. Furthermore, one Erianthus arundinaceus accession (SLC 92 87) and eight Saccharum spontaneum accessions (SLC 12 77, SLC 12 83, SLC 89 22, SLC 90 01, SLC 92 51, SLC 92 98, SLC 9299 and SLC 93 01) were selected as the best clones for nobilisation. 
Table 5. List of sub-sect of parental combinations (25) out of 2,500 to illustrate the expected outcome of the progeny

\begin{tabular}{|c|c|c|c|c|}
\hline $\begin{array}{l}\text { Parent clone } \\
\text { (classified for } \\
\text { high cane yield by } \\
\text { plot weight) }\end{array}$ & $\begin{array}{l}\text { Fiber content } \\
\text { of high cane } \\
\text { yielding } \\
\text { parent clone }\end{array}$ & $\begin{array}{l}\text { Parent clone } \\
\text { (classified for } \\
\text { high sugar } \\
\text { content by } \\
\text { POCS) }\end{array}$ & $\begin{array}{c}\text { Fiber content of } \\
\text { high sugar } \\
\text { yielding parent } \\
\text { clone }\end{array}$ & $\begin{array}{c}\text { Expected } \\
\text { characteristics of the } \\
\text { progeny }\end{array}$ \\
\hline LF 78960 & Very high & LF 781172 & Moderate & HCY, HSC, HFibre \\
\hline SLC 0812 & High & SL 942802 & High & HCY, HSC, HFibre \\
\hline SLC 0870 & High & LF 653695 & High & HCY, HSC, HFibre \\
\hline SLC 0862 & Moderate & LF 782222 & Moderate & HCY, HSC, MFibre \\
\hline SLC 0851 & High & SLT 4803 & High & HCY, HSC, HFibre \\
\hline SLC 1281 & Moderate & M 1353 & Moderate & HCY, HSC, MFibre \\
\hline LF 753866 & High & SLC 9133 & High & HCY, HSC, HFibre \\
\hline SLC 08118 & High & SLC 0862 & Moderate & HCY, HSC, HFibre \\
\hline SL 954129 & Moderate & SL 8708 & Moderate & HCY, HSC, MFibre \\
\hline SLC 9120 & Moderate & SL 954098 & Moderate & HCY, HSC, MFibre \\
\hline SL 954194 & Moderate & LF 7510031 & Moderate & HCY, HSC, MFibre \\
\hline SLC 08109 & High & Н 820778 & Moderate & HCY, HSC, HFibre \\
\hline SLC 0860 & High & SL 892315 & High & HCY, HSC, HFibre \\
\hline SLC 1249 & Moderate & SLC 0828 & High & HCY, HSC, HFibre \\
\hline LF 75423 & Very high & LF 755629 & Moderate & HCY, HSC, HFibre \\
\hline SL 8212 & Moderate & SLC 9120 & Moderate & HCY, HSC, MFibre \\
\hline SLC 0847 & Moderate & PH 8662 & Moderate & HCY, HSC, MFibre \\
\hline SL 892688 & Moderate & SLC 08106 & Moderate & HCY, HSC, MFibre \\
\hline Н 820778 & Moderate & C0 8723 & Moderate & HCY, HSC, MFibre \\
\hline SLC 1280 & Moderate & LF 78175 & Moderate & HCY, HSC, MFibre \\
\hline SL 8505 & Moderate & SL 942354 & High & HCY, HSC, HFibre \\
\hline SLC 08106 & Moderate & SLC 1205 & Moderate & HCY, HSC, MFibre \\
\hline SLC 9105 & High & SLC 0893 & Moderate & HCY, HSC, HFibre \\
\hline SLC 0816 & High & N 50219 & High & HCY, HSC, HFibre \\
\hline SLC 0817 & High & SLC 1285 & Moderate & HCY, HSC, HFiber \\
\hline
\end{tabular}

*Note: $\mathrm{HCY}=$ high cane yield, HSC = high sugar content, HFibre $=$ high fiber and MFibre = moderate fiber

As sugarcane is used also for generating energy, the requirement is to breed not only for high cane and sugar yield but also for moderate fiber content. In this study, 109 accessions were identified as having overall high cane yield, sugar content and moderate fiber content and another 38 accessions were classified as having high cane yield, high sugar content and high fiber content. These parental clones can be used in crosses directed for simultaneous improvement of all three traits.

Using the estimated breeding values for cane yield and sugar content, 50 accessions (best 10\%) were identified as parents for directional breeding of the respective traits. Of these, 08 accessions (H 820778, M 1356, SL 89 2688, SLC 08 106, SLC 08 62, SLC 12 05, SLC 8704 and SLC 91 20) were selected as the most promising, for use as parents in the simultaneous improvement of cane yield and sugar content while maintaining moderate fiber content.

Parents in the core-collections developed for high cane yield and high sugar content can be used for making a large number of bi-parental crosses, poly crosses and self-crosses. Development of a computer program is proposed to identify all possible cross combinations which will be useful in the development of the proven crossing system.

\section{ACKNOWLEDGEMENT}

The present research has been exceptionally supported by Sugarcane Research Institute, Uda-Walawe, Sri Lanka. Hence, the authors are grateful for the former Director/Chief 
Executive Officer of Sugarcane Research Institute (SRI) for granting permission to conduct this research work and for offering

\section{REFERENCES}

Central Bank of Sri Lanka. (2016). Annual report.

Central Bank of Sri Lanka. (2017). Annual report.

Central Bank of Sri Lanka. (2018). Annual report.

Central Bank of Sri Lanka. (2019). Annual report.

Contreras, A.M., Rosa, E., PERZ, M., Van Langenhove, H. and Dewulf, J. (2009). Comparative life cycle assessment of four alternatives for using byproducts of cane sugar production. Journal of Cleaner Production. 17(2), 772-779.

De Silva, A.G.S.D. Nadanasabapathy, S. Seneviratne, C.J. and Perera, S.K. (2019). Analysis of the factors affecting farmer's perception towards the sugarcane cultivation of small scale farmers in Monaragala district of Sri Lanka. International Journal of advanced scientific research. 4(1), 35-38.

Falconer, D.S. (1989). Introduction to quantitative genetics. Second edition, Longmans, London.

Keerthipala, A.P. (2014). Restructuring the sugar industry of Sri Lanka: Role of sugarcane R\&D. Proceedings of the International Sugar Conference (IS-2014), Green Technologies for Sustainable Growth of Sugar and Integrated Industries in Developing Countries, 25-28 November 2014, Academic Exchange Center of Guangxi Academy of Agricultural Sciences (GXAAS) in Nanning, China, pp. 148-151.

Keerthipala, A.P. (2016). Development of sugar industry in Sri Lanka. Sugar Technology. 18(6), 612-626.

Marshall, K. (2008). Properties of estimating breeding values. IAEA Regional training course on selective breeding and gene technologies [On line]. [Accessed on 5.2.2011]. Available at http:/www-naweb.iaea.org/nafa/aph/ estimating_BVs.pdf innumerable support in many ways for the success of the whole research work.

Mbuma, N.W. Zhou, M.M. and van der Merwe, R. (2019). Estimating breeding values of genotypes for sugarcane yield using data from unselected progeny populations. Euphytica. 216 (2), 1-15.Milovanovic, V. and Smutka, L. (2016). South Asian countries in the global sugar market: A critical assessment. Sugar Tech. 18(6), 647-658.

Ministry of Finance. (2016). Development policy for sugar industry in Sri Lanka. 1-29.

OECD-FAO (2019). OECD-FAO Agricultural outlook 2019-2028. Rome, Italy, pp 154-164.

Rencher, A.C. (2002). Methods of multivariate analysis. $2^{\text {nd }}$ ed. John Wiley \& Sons, USA. 451497.

Sugarcane Research Institute. (2013). Corporate plan of the Sugarcane Research Institute for 2013 - 2017. Sugarcane Research Institute, Uda Walawe, Sri Lanka.

Sunil, H.K. (1995). Evaluation and utilization of Saccharum germplasm in sugarcane breeding. PhD thesis, University of Birmingham, UK.

Sunil, H.K. \& Lawrence, M.J. (1996). Quantitative genetics of sugarcane. I. A large -scale evaluation of Saccharum germplasm., Sugarcane. 6, 3-10.

Wijesuriya, A. (2012). Cross prediction for directional breeding of sugarcane (Saccharum hybrid spp.) using the analysis of biparental and poly cross families. PhD thesis, University of Peradeniya, Sri Lanka.

Wijesuriya, A., Thattil, R.O. \& and Perera, A.L.T. (1993). Selection criteria used in clonal evaluation of sugarcane (Saccharum Hybrid spp.), Tropical Agriculture Research. 5:109119.

Wijesuriya, A., Thattil, R.O. \& Perera, A.L.T. (1997). Rank based selection indices for clonal evaluation of sugarcane (Saccharum Hybrid spp.), Tropical Agriculture Research. 9, 26-36. 